\title{
Meiotic pairing of sex chromosome fragments and its relation to atypical transmission of a sex-linked marker in Ephestia kuehniella (Insecta: Lepidoptera)
}

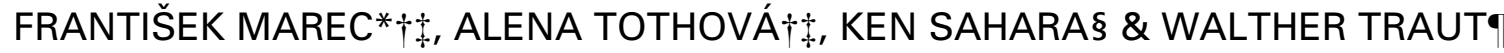 \\ $\dagger$ Department of Genetics, Institute of Entomology, Czech Academy of Sciences, Branišovská 31, \\ CZ-370 05 České Budějovice, Czech Republic, $₫$ Faculty of Biological Sciences, University of South Bohemia, \\ Branišovská 31, CZ-370 05 České Budějovice, Czech Republic, §Department of Applied Bioscience, \\ Graduate School of Agriculture, Hokkaido University, Sapporo 060-8589, Japan \\ and $\uparrow$ Institut für Biologie, Medizinische Universität zu Lübeck, D-23538 Lübeck, Germany
}

The physical basis of non-Mendelian segregation of a sex-linked marker was studied in sexchromosome mutant females of eight ASF ('abnormal segregating females') lines in the flour moth, Ephestia kuehniella. Electron microscopical analysis of microspread synaptonemal complexes revealed that in one line, the $\mathrm{Z}$ chromosome segment that contained the $d z^{+}$allele was translocated onto an autosome. The resulting quadrivalent visible in early female meiosis was 'corrected' into two bivalents in later stages. This explains autosomal inheritance of the sex chromosome marker in this strain. In the other seven ASF lines, the type of meiotic pairing of an additional fragment $\left(\mathrm{Z}^{d z+}\right)$ of the $\mathrm{Z}$ chromosome was responsible for abnormal segregation of the marker gene. In several of these lines, $\mathrm{Z}^{d z+}$ contained a piece of the $\mathrm{W}$ chromosome in addition to the $\mathrm{Z}$ segment, as was confirmed by comparative genomic hybridization $(\mathrm{CGH}) . \mathrm{Z}^{d z+}$ formed three alternative pairing configurations with the original sex chromosomes: (i) a WZZ ${ }^{d z+}$ trivalent, (ii) a WZ bivalent and a $Z^{d z+}$ univalent or (iii) a $\mathrm{ZZ}^{d z+}$ bivalent and a $\mathrm{W}$ univalent. In the most frequent $\mathrm{WZZ}^{d z+}$ configuration, $\mathrm{Z}^{d z+}$ synapsed with $\mathrm{Z}$ and, consequently, segregated with $\mathrm{W}$, simulating $\mathrm{W}$ linkage. This explains the predominant occurrence of the parental phenotypes in the progeny. $\mathrm{Z}^{d z+}$ univalents or $\mathrm{W}$ univalents, on the other hand, segregated randomly, resulting in both parental and nonparental phenotypes. In two of these lines, the $\mathrm{Z}^{d z+}$ was transmitted only to females. The results suggest that the $\mathrm{W}$ chromosome segment in $\mathrm{Z}^{d z+}$ of these lines contains a male-killing factor which makes it incompatible with male development. Our data provide direct evidence for the regular transmission of radiation-induced fragments from lepidopteran chromosomes through more than 50 generations. This is facilitated by the holokinetic nature of lepidopteran chromosomes. We conclude that $Z^{d z+}$ fragments may persist as long as they possess active kinetochore elements.

Keywords: $\mathrm{CGH}$, chromosome aberrations, male-killing factor, meiotic pairing, sex chromosomes, synaptonemal complex.

\section{Introduction}

In meiotic prophase I, homologous chromosomes synapse via the synaptonemal complex (SC) which mediates intimate association throughout their entire length. This is also true for the pairing of sex chromosomes, either $\mathrm{XX}$ or $\mathrm{ZZ}$, in the homogametic sex. In the heterogametic sex, however, various degrees of pairing can be seen, from the complete absence of

\footnotetext{
*Correspondence. E-mail: marec@entu.cas.cz
}

synaptic pairing through partial synapsis to complete synapsis, depending on the sex-chromosome system and the degree of homology between the heterologous sex chromosomes (review: John, 1990). Females of moths and butterflies (Lepidoptera) are rather exceptional in this respect. Their $\mathrm{W}$ and $\mathrm{Z}$ chromosomes, though often largely nonhomologous and of different size (Traut \& Marec, 1997) pair completely and form regular SCs (Weith \& Traut, 1986). Meiosis is achiasmatic in female Lepidoptera (Rasmussen, 1977a; Traut, 1977). The mode of heterosynapsis, including synaptic 
adjustment of the WZ bivalent in lepidopteran females (Marec \& Traut, 1994), is very similar to that observed in the WZ bivalent of bird females (Hogan et al., 1992; Solari, 1992; Pigozzi \& Solari, 1999), i.e. in distant animals having the same sex chromosome system. It is not clear, however, how the specificity of $\mathrm{W}-\mathrm{Z}$ pairing is achieved.

Inheritance of sex chromosomes as well as that of $\mathrm{X}$ - or Z-linked markers follows the Mendelian backcross scheme. The backcross type of inheritance is a device for a $1: 1$ sex ratio in the progeny and requires regular disjunction of $\mathrm{X}$ and $\mathrm{Y}$ or $\mathrm{W}$ and $\mathrm{Z}$. This is ensured by pairing. The importance of pairing for chromosome disjunction is particularly evident when meiosis is achiasmatic. For example, Drosophila males do not form SCs; somatic pairing adopts the role of meiotic pairing (McKee et al., 1992; Ault \& Rieder, 1994). Achiasmatic pairing also plays a crucial role in cases when single bivalents contain no chiasma, as often met with in chromosome 4 of D. melanogaster females (Hawley et al., 1992; McKee, 1996). For pairing followed by achiasmate segregation the term 'distributive pairing' was introduced (Grell, 1971). In the human, distributive pairing has been associated with a risk of aneuploidy (review: Kovaleva, 1992). However, this does not apply to the achiasmatic meiosis of lepidopteran females, in which modified SCs mediate bivalent pairing until metaphase I, and thus substitute the function of chiasmata beyond the pachytene stage (Rasmussen, 1977a).

In a series of radiation experiments conducted in the Mediterranean flour moth, Ephestia kuehniella, to induce $\mathrm{T}(\mathrm{W} ; \mathrm{Z})$ translocations, 12 sex-chromosome mutant lines had been isolated using a Z-linked marker, $d z$ (Marec \& Mirchi, 1990). In four lines, females carried the required translocation (Marec \& Traut, 1994). In the remaining so-called ASF ('abnormal segregating females') lines, sex-chromosome mutant females exhibited non-Mendelian segregation of the Z-linked marker. A preliminary study revealed that ASF females possess in their genome an additional segment of the $\mathrm{Z}$ chromosome (designated $\mathrm{Z}^{d z+}$ ) which includes the dominant wild-type allele of the marker gene. However, this segment was not translocated onto the W chromosome; it was translocated to an autosome in one ASF line and was present as an extra chromosome in seven other ASF lines (Marec \& Traut, 1993a).

Here we investigate meiotic pairing of sex chromosomes and their derivatives in ASF females of E. kuehniella. We show that the meiotic pairing configurations are responsible for non-Mendelian segregation of the Z-linked marker in ASF lines. In addition, our data give evidence that radiation-induced fragments of lepidopteran chromosomes are regularly inherited by both somatic and germ cells and can be transmitted through more than 50 generations.

\section{Materials and methods}

\section{Insects}

We used two laboratory wild-type strains of the Mediterranean flour moth, E. kuehniella Zeller (Lepidoptera: Pyralidae), WT-C and WT-L (Marec \& Traut, 1994). Eight ASF lines, designated ASF-1 to ASF-8, were examined for sex-chromosome constitution. The lines had been isolated using the sex-linked recessive marker $d z$ (dark central area of the forewings; Kühn, 1939) from crosses between gamma-ray treated WT-C females $\left(d z^{+} /-\right)$and untreated $d z$ males $(d z / d z)$ (Marec \& Mirchi, 1990). Sex-chromosome mutant females of wild-type (i.e. possessing a $d z / d z^{+}$ genotype) were repeatedly backcrossed with males of the $d z$ strain to separate the mutation from other induced genetic alterations. Since then, each ASF line has been kept in single-pair cultures by crosses between $d z / d z^{+}$females and their $d z / d z$ male siblings (Fig. 1). In ASF lines, nonparental phenotypes ( $d z$ females and wild-type males) segregated besides the parental phenotypes (wild-type females and $d z$ males) in atypical ratios that were specific for each ASF line (Table 1).

\section{LM preparations}

Spread chromosome preparations of pachytene cells from fifth-instar female larvae were made according to a

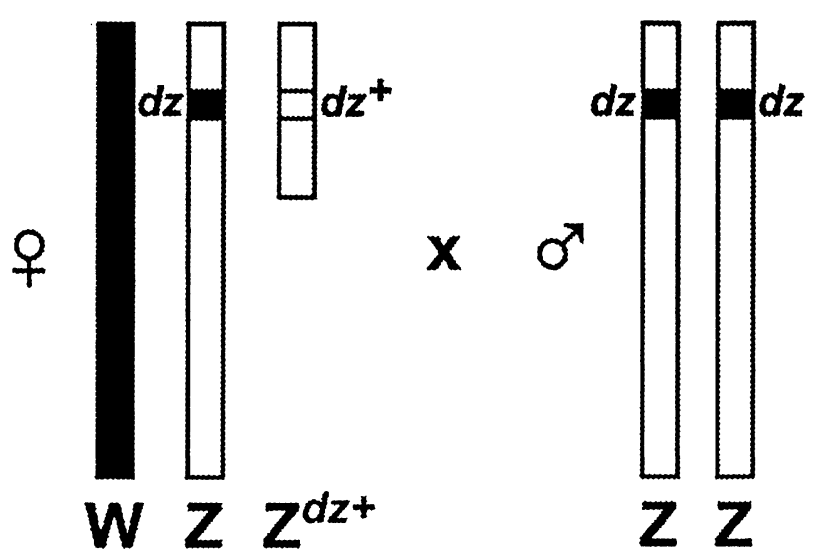

Fig. 1 A scheme of crosses between mutant (phenotypically wild-type) females and $d z$ males in ASF lines of Ephestia kuehniella. $\mathrm{W}$ and $\mathrm{Z}$, sex chromosomes; $\mathrm{Z}^{d z+}$, a fragment of the $\mathrm{Z}$ chromosome carrying a $d z^{+}$allele. In the ASF-3 line, the same type of crosses was used but the $d z^{+}$allele was translocated onto an autosome. 
Table 1 Segregation data (from Marec \& Mirchi, 1990) in ASF lines of Ephestia kuehniella. In each mutant line and in the control, progeny originated from crosses between wildtype females $(+)$ and $d z$ males

\begin{tabular}{|c|c|c|c|c|c|c|}
\hline \multirow{2}{*}{$\begin{array}{l}\text { Line } \\
\text { code }\end{array}$} & \multirow{2}{*}{$\begin{array}{c}\text { Total no. of } \\
\text { progeny }\end{array}$} & \multicolumn{4}{|c|}{ Segregation in progeny $(\%)$} & \multirow[b]{2}{*}{ q $: \hat{o}$ ratio } \\
\hline & & $q+$ & + $d z$ & $\hat{o}+$ & $\hat{o} d z$ & \\
\hline ASF-1 & 3585 & 40.5 & 11.8 & - & 47.7 & 1.10 \\
\hline ASF-2 & 2579 & 38.6 & 17.1 & - & 44.3 & 1.26 \\
\hline ASF-3 & 2096 & 32.0 & 33.6 & - & 34.5 & 1.90 \\
\hline ASF-4 & 3093 & 36.8 & 9.0 & 11.1 & 43.1 & 0.84 \\
\hline ASF-5 & 4504 & 33.2 & 15.7 & 14.4 & 36.8 & 0.96 \\
\hline ASF-6 & 3478 & 32.7 & 14.0 & 15.6 & 37.8 & 0.87 \\
\hline ASF-7 & 2556 & 32.8 & 16.7 & 13.7 & 36.9 & 0.98 \\
\hline ASF-8 & 601 & 29.8 & 8.5 & 11.5 & 50.2 & 0.62 \\
\hline Control & 1414 & - & 52.1 & 47.9 & - & 1.09 \\
\hline
\end{tabular}

pachytene mapping technique (Traut, 1976), stained with lactic acetic orcein and examined with phase contrast microscopy (details in Marec \& Traut, 1994).

Preparations of metaphase I chromosomes were made from mature oocytes of virgin adult females. Ovaries were dissected out in a saline and fixed in freshly prepared Carnoy fixative (ethanol, chloroform, acetic acid, 6:3:1) for $5 \mathrm{~min}$. Distal ends of ovarioles were squashed in a drop of $60 \%$ acetic acid. Then the preparations were frozen on dry ice and, after removal of coverslips, dehydrated in $96 \%$ ethanol for $5 \mathrm{~min}$, air-dried, stained and mounted in $10 \mu \mathrm{g} / \mathrm{mL}$ DAPI (4',6-diamidino-2-phenylindole; Sigma) in Mcllvaine's buffer (18 mm citric acid, $164 \mathrm{~mm} \mathrm{Na}_{2} \mathrm{HPO}_{4}, \mathrm{pH}$ 7), and sealed with nail varnish.

\section{EM preparations of pachytene chromosomes}

Meiotic pairing of sex chromosomes was studied by using the EM microspreading technique of Miller \& Bakken (1972) which yields preparations of pachytene synaptonemal complexes (SCs) with associated chromatin (review: Marec, 1996). The procedure given in Marec \& Traut (1993b) was followed. Preparations were examined and micrographs taken in a Philips EM 400 transmission electron microscope operated at $80 \mathrm{kV}$. Lateral elements (LEs) of sex chromosome SCs, each LE representing the axis of one chromosome, were measured from EM micrographs using a digitizer tablet and two computer programs, MESSCHRO and EVALCHRO (written by W.T.).

\section{Comparative genomic hybridization (CGH)}

Spread chromosome preparations were made from pachytene cells of fifth-instar female larvae as described by Traut et al. (1999). Whole genomic DNAs were isolated separately from female and male larvae of the WT-L strain. Labelling was done by nick translation using the Bionick Labelling system (GibcoBRL, Life
Technologies, Karlsruhe, Germany). DNA of females was labelled with FluorX-dCTP (green), DNA of males with Cy3-dCTP (red) (Amersham Life Science, Arlington Heights, Illinois).

CGH was carried out according to Lapierre et al. (1998) with slight modifications. The probe mixture for one slide $(10 \mu \mathrm{L}, 50 \%$ formamide, $10 \%$ dextran sulphate, $2 \times$ SSC) contained 750 ng labelled DNA from females, $250 \mathrm{ng}$ labelled DNA from males, $3 \mu \mathrm{g}$ unlabelled sonicated competitor DNA from males, and $25 \mu \mathrm{g}$ salmon sperm DNA. Hybridization was for 3 days at $37^{\circ} \mathrm{C}$. A stringent wash at $62^{\circ} \mathrm{C}$ in $0.1 \times \mathrm{SSC}, 1 \%$ Triton $\mathrm{X}-100$, was followed by washes at room temperature and counterstaining in $0.1 \mu \mathrm{g} / \mathrm{mL}$ DAPI (4',6-diamidino-2-phenylindole; Sigma) for $1 \mathrm{~min}$ and mounting in antifade $(0.233 \mathrm{~g}$ DABCO [1,4-diazobicyclo(2.2.2)-octane; Sigma] in $1 \mathrm{~mL} 0.2 \mathrm{M}$ Tris- $\mathrm{HCl}$, $\mathrm{pH} 8.0$, and $9 \mathrm{~mL}$ glycerol).

Black-and-white images of the chromosomes were recorded separately for each fluorescent dye with a cooled CCD camera using the Pinkel filter set for the Zeiss Axioskop microscope. False colouring and superposition of images was done with an image processing program, Adobe РнотоSноP version 5.0. Routinely, green colour was adopted for the female probe, red for the male probe, and light blue for the DAPI image.

\section{Results}

WT-C

Wild-type karyotypes of Ephestia display 30 bivalents, each forming an SC, in microspread EM preparations of pachytene cells from female meiosis (Marec \& Traut, 1993b). In most nuclei, the WZ bivalent can be identified according to different lengths of LEs, delayed pairing, and the remnants of compact heterochromatin tangles decorating the $\mathrm{W}$ chromosome LE (Weith \& Traut, 1986). Measurements revealed that the $\mathrm{W}$ chromosome LE in WT-C females was on average $20 \%$ shorter than 
the $\mathrm{Z}$ chromosome LE (Table 2). Sixty percent of $49 \mathrm{WZ}$ bivalents were completely paired, often showing characteristic twisting of the longer $\mathrm{Z}$ along the shorter $\mathrm{W}$ (Marec \& Traut, 1994).

In LM preparations of pachytene nuclei examined from five WT-C females, the WZ bivalent was easily identified by the heterochromatic thread of the W chromosome. In most nuclei, the $\mathrm{W}$ was composed of two large heterochromatic segments of a similar size, separated by a weakly stained gap (Fig. 2a); in some nuclei with longer pachytene bivalents, the $\mathrm{W}$ formed 3-4 heterochromatic blocks. This $\mathrm{W}$ morphology is typical for the WT-C strain but not for the WT-L strain, in which the WZ bivalents mostly form a continuous thread without a gap (cf. Marec \& Traut, 1994). The longer $\mathrm{Z}$ chromosome was twisted along the shorter $\mathrm{W}$ to adjust for pairing. The $\mathrm{Z}$, like the autosomes, displayed a characteristic chromomere/interchromomere pattern. In favourable WZ bivalents, a total of 14 (12-16) chromomeres were observed, and two of them were particularly conspicuous: the 5th and 6th chromomeres when counted from the nearest end, as in Fig. 2a (arrowheads). A similar pattern was observed in the $\mathrm{Z}$ of ASF lines (Fig. 2d), although this chromosome originated from the $d z$ mutant strain isolated from a different geographical population more than 60 years ago (Kühn, 1939).

\section{ASF-1 and ASF-2}

The ASF-1 and ASF-2 lines exhibited very similar segregation data, with the $d z^{+}$allele transmitted exclusively to female progeny (Table 1 ). The cytogenetic characteristics of the two lines were also similar. In EM preparations of most ASF-1 and ASF-2 female larvae, the pachytene complements displayed a fragment (designated $\mathrm{Z}^{d z+}$ ) of the $\mathrm{Z}$ chromosome in addition to the normal $\mathrm{Z}$ chromosome. This fragment was relatively big, constituting about $40 \%$ of the $\mathrm{Z}$ chromosome length (Table 2). In females with $Z^{d z+}\left(d z / d z^{+}\right.$genotype) and without $\mathrm{Z}^{d z+}(d z /-$ genotype), the $\mathrm{W}$ chromosome of these lines (designated $\mathrm{W}^{\mathrm{del}}$ ) was $40 \%$ smaller than the $\mathrm{Z}$ and $20 \%$ smaller than the normal $\mathrm{W}$; it had evidently suffered a deletion. Three main types of pairing configurations of sex chromosomes were observed in females possessing the $\mathrm{Z}^{d z+}$ fragment: a $\mathrm{W}^{\mathrm{del}} \mathrm{ZZ}^{d z+}$ trivalent, a $\mathrm{W}^{\mathrm{del}} \mathrm{Z}$ bivalent plus a $\mathrm{Z}^{d z+}$ univalent, and a $\mathrm{ZZ}^{d z+}$ bivalent plus a $\mathrm{W}^{\mathrm{del}}$ univalent (for schematic representations and frequencies, see Fig. 3a). In most pachytene nuclei, the $\mathrm{Z}^{d z+}$ was paired with the $\mathrm{Z}$ and $\mathrm{W}^{\mathrm{del}}$ in a trivalent (Fig. 4a,b,e,f). In ASF-1 females, complete pairing of the $\mathrm{W}^{\text {del }} \mathrm{ZZ}^{d z+}$ trivalent predominated (Fig. 4a). ASF-2 females displayed incomplete pairing of the $\mathrm{Z}^{d z+}$ and/or $\mathrm{W}^{\mathrm{del}}$ with the $\mathrm{Z}$ (Fig. 4e) almost as often as fully synapsed trivalents (Fig. 4f). A smaller fraction of nuclei showed a $Z^{d z+}$ univalent that was self-paired (Fig. 4c,g) besides a $\mathrm{W}^{\text {del }} \mathrm{Z}$ bivalent. The bivalent showed various pairing patterns, from a bivalent adjusted for synapsis by twisting of the longer $\mathrm{Z}$ along the shorter $\mathrm{W}$ (Fig. 4c) to an uneven bivalent with an unpaired terminal segment of the $\mathrm{Z}$ (Fig. 4g). Similar pairing patterns of the $\mathrm{W}^{\mathrm{del}} \mathrm{Z}$ bivalent were also observed in females without $\mathrm{Z}^{d z+}$. Finally, several nuclei in ASF-1 females and one-third of the nuclei in ASF-2 females displayed a $\mathrm{ZZ}^{d z+}$ bivalent plus a $\mathrm{W}^{\text {del }}$ univalent that either formed a straight thread (Fig. 4d)

Table 2 Mean lengths of lateral elements (LEs) of sex chromosome synaptonemal complexes (SCs) in microspread pachytene oocytes of ASF females of Ephestia kuehniella

\begin{tabular}{|c|c|c|c|c|c|c|c|}
\hline \multirow{2}{*}{$\begin{array}{l}\text { Females } \\
\text { examined }\end{array}$} & \multirow[b]{2}{*}{$N$} & \multicolumn{3}{|c|}{ Mean LE lengths $(\mu \mathrm{m})$} & \multicolumn{2}{|c|}{ Relative LE lengths (\%) } & \\
\hline & & $\mathrm{Z}$ & $\mathrm{W}\left(\mathrm{W}^{\mathrm{del}}\right)$ & $\mathrm{Z}^{d z+}$ & $\mathrm{W} / \mathrm{Z}$ & $\mathrm{Z}^{d z+} / \mathrm{Z}$ & \\
\hline WT-C & 47 & $6.7 \pm 1.5$ & $5.3 \pm 1.1$ & - & $79.5 \pm 7.7$ & - & \\
\hline ASF-1 + & 36 & $7.3 \pm 1.3$ & $4.4 \pm 0.9$ & $2.9 \pm 0.6$ & $61.4 \pm 10.2$ & $40.7 \pm 5.1$ & \\
\hline ASF-1 $d z$ & 8 & $8.3 \pm 1.5$ & $4.5 \pm 0.9$ & - & $55.1 \pm 6.3$ & - & \\
\hline $\mathrm{ASF}-2+$ & 45 & $7.2 \pm 1.3$ & $4.4 \pm 0.9$ & $3.0 \pm 0.6$ & $61.7 \pm 8.0$ & $42.4 \pm 5.0$ & \\
\hline ASF-4 + & 41 & $7.4 \pm 1.6$ & $4.6 \pm 0.9$ & $3.4 \pm 0.7$ & $63.7 \pm 8.7$ & $47.6 \pm 9.4$ & \\
\hline ASF-5 + & 30 & $7.5 \pm 1.2$ & $5.7 \pm 0.9$ & $2.6 \pm 0.4$ & $77.3 \pm 9.7$ & $34.7 \pm 6.5$ & \\
\hline ASF-6 + & 24 & $7.3 \pm 1.3$ & $5.3 \pm 1.0$ & $2.3 \pm 0.4$ & $73.5 \pm 10.9$ & $31.9 \pm 6.5$ & \\
\hline ASF-7 + & 32 & $6.6 \pm 1.1$ & $4.6 \pm 0.9$ & $2.2 \pm 0.5$ & $70.3 \pm 11.5$ & $33.2 \pm 8.3$ & \\
\hline ASF-8 + & 21 & $8.1 \pm 1.3$ & $5.6 \pm 1.0$ & $3.2 \pm 0.7$ & $69.9 \pm 12.3$ & $39.3 \pm 10.3$ & \\
\hline \multirow[t]{2}{*}{ ASF-8 $d z$} & 10 & $6.8 \pm 0.6$ & $5.2 \pm 0.5$ & - & $76.9 \pm 6.7$ & - & \\
\hline & & $\mathrm{Z}$ & W & $A^{Z}$ & A & $\mathrm{W} / \mathrm{Z}$ & $\mathrm{A}^{\mathrm{Z}} / \mathrm{A}$ \\
\hline ASF-3 + & 31 & $7.8 \pm 1.7$ & $5.8 \pm 0.8$ & $5.0 \pm 1.3$ & $4.0 \pm 1.1$ & $76.7 \pm 12.6$ & $127.2 \pm 13.8$ \\
\hline $\mathrm{ASF}-3 d z$ & 12 & $7.8 \pm 2.6$ & $6.4 \pm 1.5$ & - & - & $84.1 \pm 8.0$ & - \\
\hline
\end{tabular}




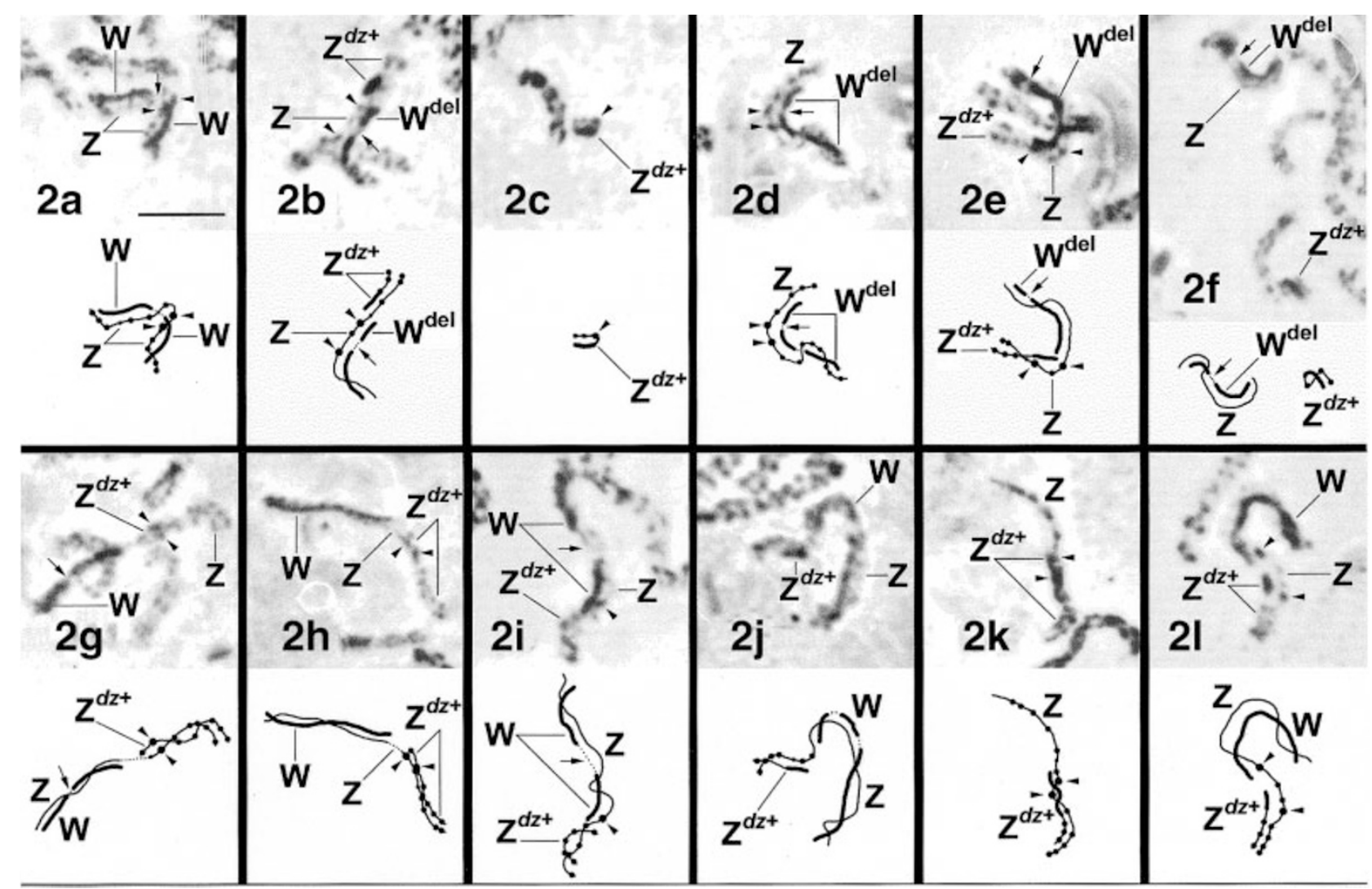

Fig. 2 Pachytene patterns of sex chromosome synapsis in spread cells from female meiosis (phase contrast micrographs), stained with lactic acetic orcein, of the WT-C strain and ASF lines of Ephestia kuehniella. W (thick line) and Z (thin line, dots indicate chromomere pattern), sex chromosomes; $\mathrm{Z}^{d z+}$, a fragment of the $\mathrm{Z}$ chromosome carrying a $d z^{+}$allele; $\mathrm{W}^{\text {del }}$, a deficient $\mathrm{W}$ chromosome. Arrowheads indicate 1-2 conspicuous chromomeres that were regularly observed in the WT-C strain (see text). Arrows indicate a weakly stained gap between two large heterochromatic segments of the W chromosome. (a) WT-C strain: WZ bivalent. Fig. 2b,c. ASF-1 line: (b) $\mathrm{W}^{\text {del }} Z^{d z+}$ trivalent; (c) self-paired $Z^{d z+}$ univalent. Fig. $2 d-f$. ASF-2 line: (d) $W^{\text {del }} Z$ bivalent; (e) $\mathrm{W}^{\text {del }} Z Z^{d z+}$ trivalent; (f) $\mathrm{W}^{\text {del }} Z$ bivalent and self-paired $Z^{d z+}$ univalent. Fig. g,h. ASF-4 line: WZZ ${ }^{d z+}$ trivalents. (i) ASF-5 line: $\mathrm{WZZ}^{d z+}$ trivalent. Fig. 2 j,k. ASF-6 line: (j) WZZ ${ }^{d z+}$ trivalent; (k) ZZ ${ }^{d z+}$ bivalent. (1) ASF-7 line: WZZ ${ }^{d z+}$ trivalent. Scale bar $=5 \mu$ m.

or was self-paired (Fig. 4h). The $\mathrm{Z}$ and $\mathrm{Z}^{d z+}$ chromosomes formed either an uneven bivalent similar to the $\mathrm{W}^{\text {del }} \mathrm{Z}$ bivalent or formed a looped bivalent with both terminal segments paired (Fig. 4d,h). Twisting of the $\mathrm{Z}$ along the $Z^{d z+}$ was never observed, probably because of the excessive difference in lengths.

The $\mathrm{W}^{\mathrm{del}}$ chromosome in ASF-1 and ASF-2 females regularly displayed the typical remnants of heterochromatin tangles (e.g. Fig. 4a,b,d,f). In some nuclei, similar tangles were also observed at LEs of the $\mathrm{Z}^{d z+}$ fragments (Fig. 4b,f). Taken together with the $\mathrm{W}^{\mathrm{del}}$ deficiency, these results indicate that the fragment contains a block of $\mathrm{W}$-specific heterochromatin.

A detailed analysis of LM preparations was carried out on ASF-2 females possessing the $\mathrm{Z}^{d z+}$ fragment. In a total of 51 photographed pachytene nuclei, the $\mathrm{Z}^{d z+}$ fragments formed four different pairing configurations with $\mathrm{W}^{\text {del }}$ and $\mathrm{Z}$ chromosomes. A $\mathrm{W}^{\mathrm{del}} \mathrm{ZZ}^{d z+}$ trivalent (Fig. 2e) was found in $59 \%$ of nuclei. $\mathrm{A} \quad \mathrm{W}^{\mathrm{del}} \mathrm{Z}$ bivalent plus a $\mathrm{Z}^{d z+}$ univalent that was mostly self-paired (Fig. 2f) was found in $25 \%$ of the nuclei. Twelve percent of the nuclei showed a $\mathrm{W}^{\mathrm{del}}$ univalent plus a $\mathrm{ZZ}^{d z+}$ bivalent. In only two nuclei (4\%), a $\mathrm{W}^{\mathrm{del}} \mathrm{Z}^{d z+}$ bivalent plus a $\mathrm{Z}$ univalent were observed. Similar to the $\mathrm{W}$ in WT-C females, the $\mathrm{W}^{\text {del }}$ chromosome was often composed of two heterochromatic segments, but one segment was evidently shorter than the other, indicating a terminal deficiency at that end (Fig. 2d,f). The $\mathrm{Z}^{d z+}$ fragment consisted of a longer segment that displayed three chromomeres and of a short-terminal block of heterochromatin that comprised about $1 / 3$ of the fragment length. Inspection of a few preparations from ASF-1 females revealed a similar pattern of the $\mathrm{Z}^{d z+}$ including a terminal heterochromatin 


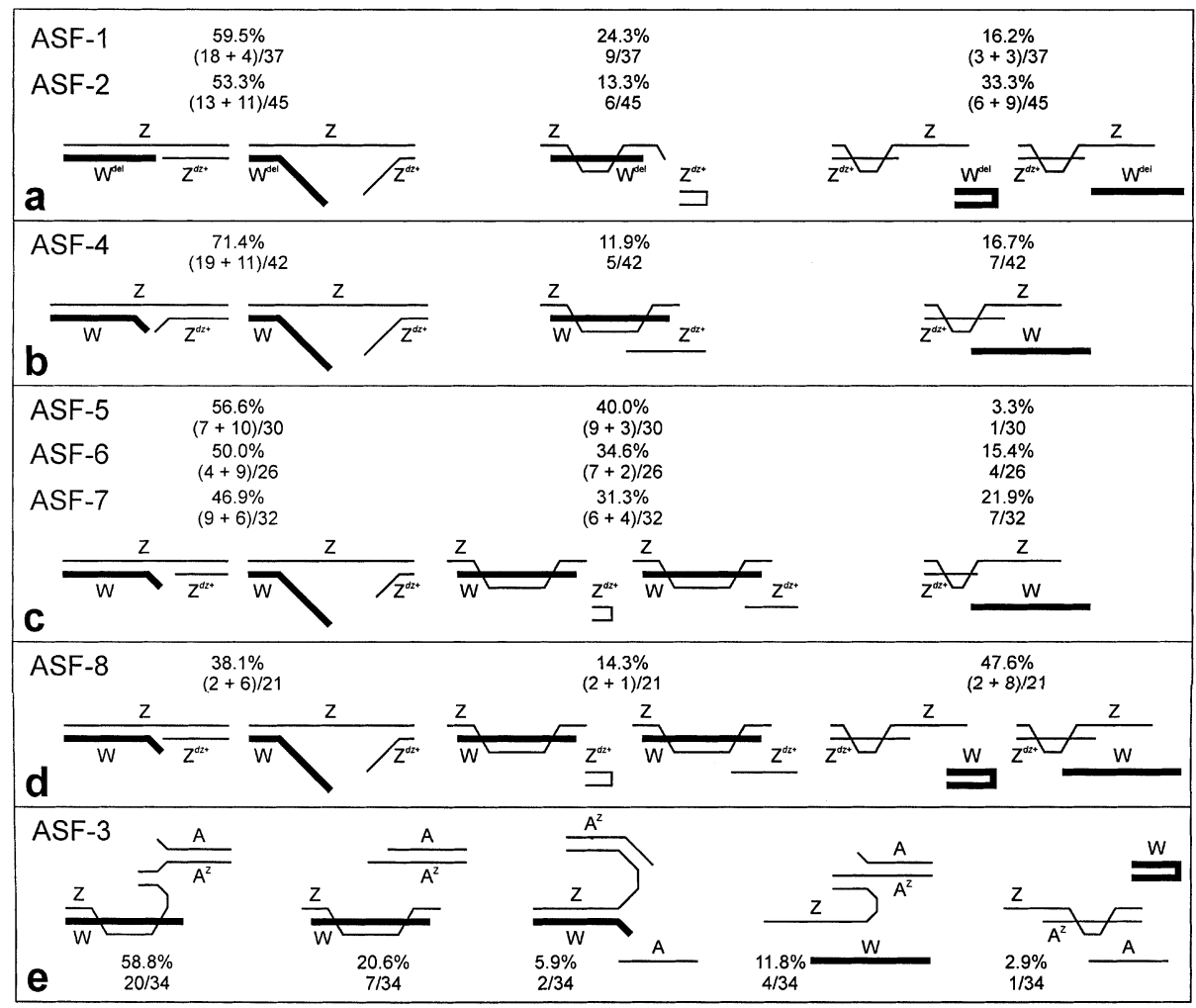

Fig. 3 Schematic illustration of sex chromosome pairing in pachytene nuclei of ASF females of Ephestia kuehniella, based on the analysis of EM micrographs. For each of ASF-1 to ASF-8 lines, percentages of pairing configurations observed are given. Numbers of nuclei with a particular configuration (before slash) and total numbers of nuclei examined (after slash) are also given. (a) ASF-1 and ASF-2 lines; (b) ASF-4 line; (c) ASF-5, ASF-6 and ASF-7 lines; (d) ASF-8 line; (e) ASF-3 line. W and Z, sex chromosomes; $Z^{d z+}$, a fragment of the $\mathrm{Z}$ chromosome carrying a $d z^{+}$allele; $\mathrm{W}^{\mathrm{del}}$, a deficient $\mathrm{W}$ chromosome; $\mathrm{A}$, an autosome; $\mathrm{A}^{\mathrm{Z}}$, a homologous autosome carrying the $\mathrm{T}(\mathrm{A} ; \mathrm{Z})$ translocation. block, but the block appeared longer and more conspicuous than in ASF-2 females (Fig. 2b,c).

In E. kuehniella, the heterochromatic W chromosome can be identified by $\mathrm{CGH}$ because of its advanced molecular differentiation from the $\mathrm{Z}$ chromosome (Traut et al., 1999; Traut, 1999). When pachytene preparations of ASF-2 females were subjected to $\mathrm{CGH}$, the female DNA probe highlighted the $\mathrm{W}^{\mathrm{del}}$ chromosome and, in addition, the terminal heterochromatic block in the $\mathrm{Z}^{d z+}$ fragment in all three basic pairing configurations, namely the $\mathrm{W}^{\mathrm{del}} \mathrm{ZZ}^{d z+}$ trivalent (Fig. 5a), the $\mathrm{ZZ}^{d z+}$ bivalent plus the $\mathrm{W}^{\mathrm{del}}$ univalent (Fig. 5b), and the $\mathrm{W}^{\mathrm{del}} \mathrm{Z}$ bivalent plus the $\mathrm{Z}^{d z+}$ univalent (Fig. 5c). Thus, CGH data unambiguously prove that the heterochromatic block in the $\mathrm{Z}^{d z+}$ fragment of ASF-2 females was derived from the $\mathrm{W}$ chromosome. In some nuclei with a trivalent, the $\mathrm{Z}^{d z+}$ fragment showed reversed pairing: it paired by its heterochromatic segment with one end of the $\mathrm{Z}$ while its euchromatic part was non-homologously paired with the inner part of the $\mathrm{Z}$ (Fig. 5d). This unusual pairing was probably a result of competition between the homologous part and the $\mathrm{W}$ chromatin part of $\mathrm{Z}^{d z+}$ in the initiation of pairing with the Z-chromosome end.

The above data on pachytene pairing of sex chromosomes in ASF females were obtained from larvae, and thus could not be related to the phenotype $\left(d z\right.$ or $\left.d z^{+}\right)$of the individual. We assumed that female larvae with $\mathrm{Z}^{d z+}$ develop to $d z^{+}$females and those without $\mathrm{Z}^{d z+}$ to $d z$ females. To confirm this assumption we examined metaphase I bivalents from mature oocytes of adult females. As expected, $d z$ females showed the 30 bivalents of the normal karyotype, whereas ASF-1 and ASF-2 $d z^{+}$females showed the additional fragment (not shown). A detailed analysis of 30 metaphase I complements from six wild-type ASF-1 females revealed only two pairing configurations. Analogously to pachytene cells, most nuclei $(66.7 \%)$ showed the $\mathrm{W}^{\mathrm{del}} \mathrm{ZZ}^{d z+}$ trivalent. The remaining nuclei $(33.3 \%)$ showed a bivalent consisting of the longer $\mathrm{Z}$ chromosome and a shorter chromosome $\left(\mathrm{W}^{\mathrm{del}}\right.$ or $\mathrm{Z}^{d z+}$ ) plus a univalent $\left(\mathrm{Z}^{d z+}\right.$ or $\left.\mathrm{W}^{\mathrm{del}}\right)$. In two $d z$ females examined, the sex chromosome bivalent $\left(\mathrm{W}^{\mathrm{del}} \mathrm{Z}\right)$ was identified according to the deficient $\mathrm{W}^{\mathrm{del}}$ chromosome (not shown).

\section{ASF-3}

In the ASF-3 line, crosses of wild-type females with $d z$ males produced wild-type females, $d z$ females, and $d z$ males at a ratio of $1: 1: 1$, whereas wild-type males were absent (Table 1). In a number of female larvae, structurally normal WZ bivalents were observed in pachytene (Fig. 4i) and no structural changes were found in their SC complements. These larvae were 


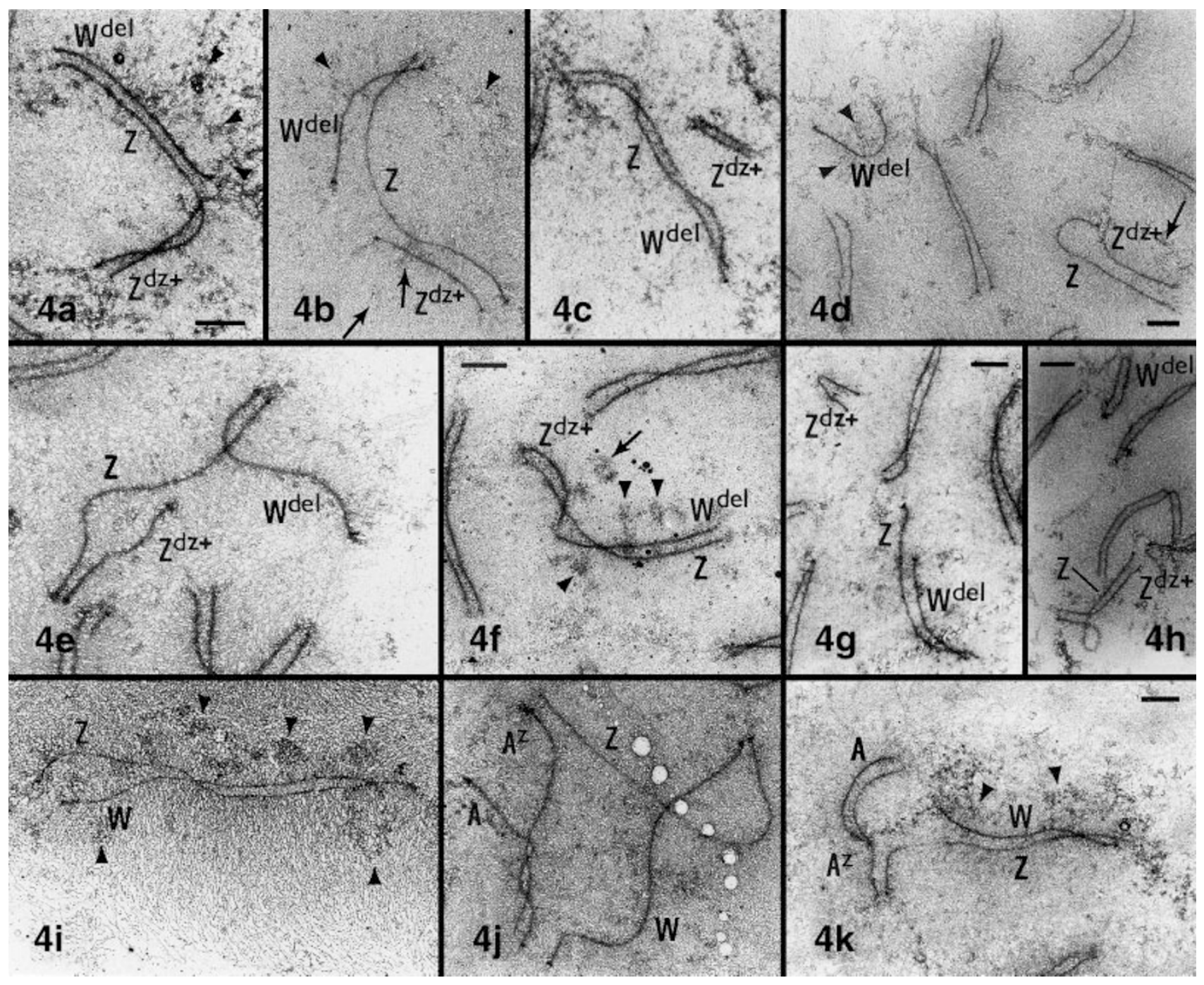

Fig. 4 Sex chromosome configurations in microspread pachytene nuclei (EM micrographs) of ASF females of Ephestia kuehniella. $\mathrm{W}$ and $\mathrm{Z}$, sex chromosomes; $\mathrm{Z}^{d z+}$, a fragment of the $\mathrm{Z}$ chromosome carrying a $d z^{+}$allele; $\mathrm{W}^{\text {del }}$, a deficient $\mathrm{W}$ chromosome. Arrowheads indicate remnants of heterochromatin tangles decorating the $\mathrm{W}$ chromosome axis. Arrows indicate remnants of heterochromatin tangles at the $\mathrm{Z}^{d z+}$ fragment. Fig. 4a-d. ASF-1 females $\left(d z^{+}\right)$: (a) fully synapsed $\mathrm{W}^{\text {del }} \mathrm{ZZ}^{d z+}$ trivalent; (b) paired but non-synapsed $\mathrm{W}^{\text {del }} \mathrm{ZZ}^{d z+}$ trivalent; (c) synaptically adjusted $\mathrm{W}^{\text {del }} \mathrm{Z}$ bivalent and self-synapsed $\mathrm{Z}^{d z+}$ univalent; (d) $\mathrm{W}^{\text {del }}$ univalent and $\mathrm{ZZ}^{d z+}$ bivalent. Fig. $4 \mathrm{e}-\mathrm{h}$. ASF-2 females $\left(d z^{+}\right)$: (e) partly paired $\mathrm{W}^{\text {del }} \mathrm{ZZ}^{d z+}$ trivalent; (f) fully synapsed $\mathrm{W}^{\text {del }} \mathrm{ZZ}^{d z+}$ trivalent; (g) uneven $\mathrm{W}^{\text {del }} \mathrm{Z}$ bivalent and self-paired $\mathrm{Z}^{d z+}$ univalent; (h) self-synapsed $\mathrm{W}^{\text {del }}$ univalent and $\mathrm{ZZ}{ }^{d z+}$ bivalent. Fig. $4 \mathrm{i}-\mathrm{k}$. ASF-3 females, (i), $d z$; (j,k), $d z^{+}$: (i) incompletely synapsed $\mathrm{WZ}$ bivalent; (j) partly paired $\mathrm{AA}^{\mathrm{Z}} \mathrm{WZ}$ quadrivalent, where $\mathrm{A}$ is an intact autosome and its $\mathrm{A}^{\mathrm{Z}}$ homologue carrying the $\mathrm{T}(\mathrm{A} ; \mathrm{Z})$ translocation; (k) well synapsed $\mathrm{AA}^{\mathrm{Z}} \mathrm{WZ}$ quadrivalent. Scale bars $=1 \mu \mathrm{m}$. Fig. $4 a, b, c, e, i, j$ have the same scale.

regarded as $d z$ females. In other ASF-3 female larvae regarded as wild-type females, a quadrivalent involving the WZ pair and an autosome pair was found in almost $60 \%$ of the nuclei (Fig. $4 \mathrm{j}$ ). Well paired configurations displayed an extended Z-chromosome LE with one end paired with a terminal segment of the longer of two autosomes while the major part was paired with the $\mathrm{W}$ chromosome (Fig. 4k). This indicates a non-reciprocal translocation $\mathrm{T}(\mathrm{A} ; \mathrm{Z})$, in which a part of the $\mathrm{Z}$ chromosome marked with the $d z^{+}$allele had been translocated onto one of the autosomes (further designated $\mathrm{A}^{\mathrm{Z}}$ ). The $\mathrm{A}^{\mathrm{Z}}$ chromosome was $27 \%$ longer than its original homologue (Table 2). Besides the quadrivalent, several other configurations were observed (Fig. 3e). In $20.6 \%$ of the nuclei, two independent bivalents $\mathrm{WZ}$ and $\mathrm{AA}^{\mathrm{Z}}$ were found; the latter could be recognized as an SC with unequal LEs. The remaining configurations showed one or two univalents

(c) The Genetics Society of Great Britain, Heredity, 87, 659-671. 

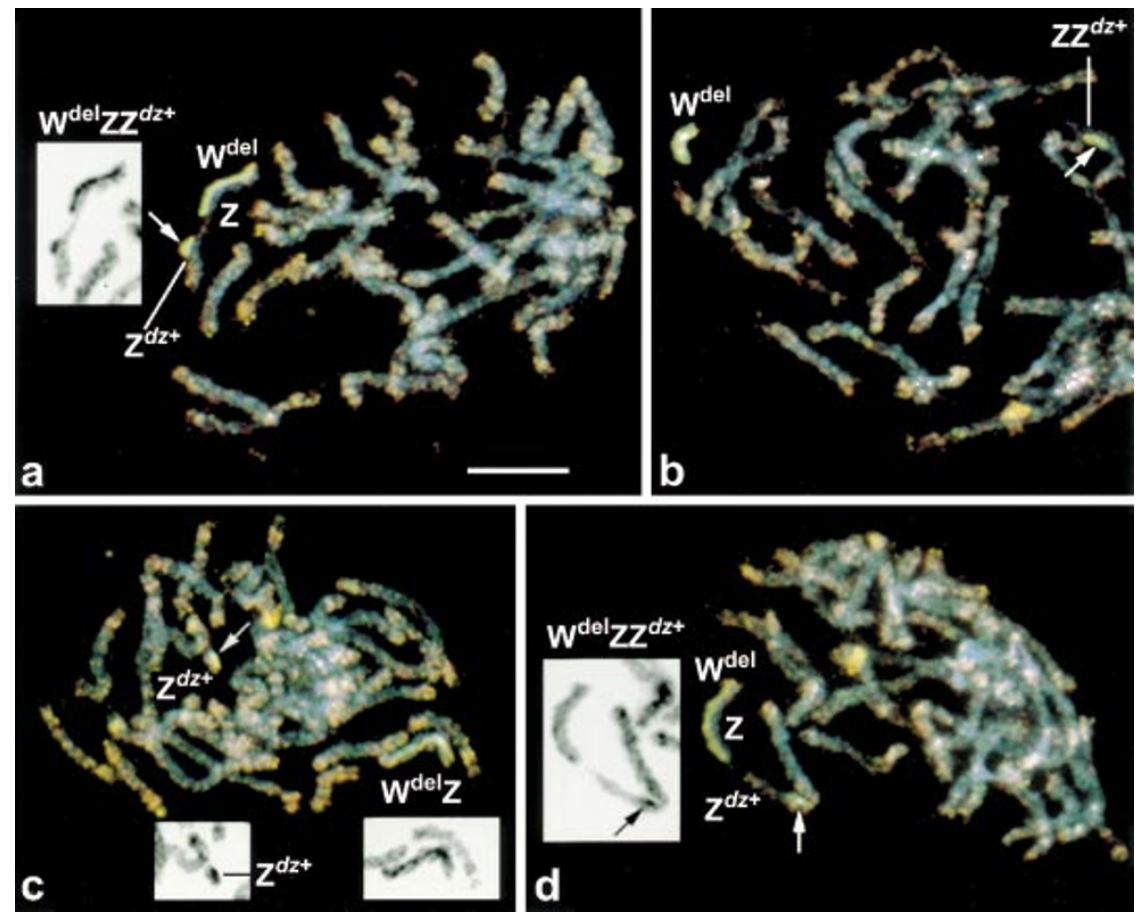

Fig. $5 \mathrm{CGH}$ on spread preparations from ovaries of ASF-2 females (black and white inserted pictures represent a section of inverted DAPI images): a pachytene complement showing a $\mathrm{W}^{\text {del }} \mathrm{ZZ}^{d z+}$ trivalent with highlighted W chromatin (green); note a block of $\mathrm{W}$ chromatin in the $\mathrm{Z}^{d z+}$ fragment (arrow); (b) pachytene oocyte showing a self-paired $\mathrm{W}^{\text {del }}$ univalent and $\mathrm{ZZ}^{d z+}$ bivalent; (c) pachytene complement showing a self-paired $\mathrm{Z}^{d z+}$ fragment and $\mathrm{W}^{\mathrm{del}} \mathrm{Z}$ bivalent; (d) $\mathrm{W}^{\text {del }} \mathrm{ZZ}^{d z+}$ trivalent showing reverse pairing of the $Z^{d z+}$ fragment. Scale bar $=10 \mu \mathrm{m}$.
(A and/or W) and most probably reflected an incomplete pairing process.

Mature oocytes of adult $d z$ females in the ASF-3 line showed 30 metaphase I bivalents (not shown). The karyotype of wild-type females was unclear. About one-half of the nuclei showed a clump or another suspicious configuration of chromosomes, whereas in others the chromosome rearrangement was undetectable (50 nuclei from eight females evaluated; Fig. 6a). Obviously, metaphase I chromosomes in E. kuehniella are too small for the detection of minor size differences.

\section{ASF-4}

Crosses of wild-type females and $d z$ males in the ASF-4 line produced both nonparental phenotypes, $d z$ females and wild-type males, at a ratio of $1: 4$ to parental phenotypes (Table 1). In EM preparations of ASF-4 female larvae possessing a $\mathrm{Z}^{d z+}$ fragment, more than $70 \%$ of pachytene nuclei showed a $\mathrm{WZZ}^{d z+}$ trivalent that was mostly well synapsed (Fig. 7a). The $Z^{d z+}$ fragment was longer than the corresponding fragments in the other ASF lines, amounting to almost one-half of the $\mathrm{Z}$ chromosome length (Table 2). Typically the $\mathrm{Z}$ chromosome LE was extended to adjust for pairing with both the $\mathrm{W}$ and $\mathrm{Z}^{d z+}$, and appeared attenuated in between (Fig. 7a,b). The W chromosome was shortened, most probably in this case as a result of synaptic adjustment rather than a deletion. The remaining nuclei ( $<30 \%)$ showed two alternative pairing configurations,
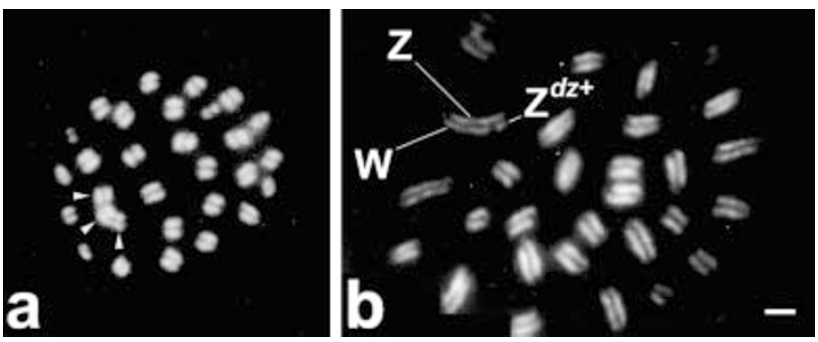

Fig. 6 DAPI stained chromosome sets of mature oocytes from adult females: (a) 30 metaphase I bivalents from a $d z^{+}$ASF-3 female (sex chromosomes and $\mathrm{T}(\mathrm{A} ; \mathrm{Z})$ translocation not identified); note a chain formed by 3 bivalents (arrowheads). (b) prometaphase I set from a $d z^{+} \mathrm{ASF}-5$ female showing a $\mathrm{WZZ}^{d z+}$ trivalent. $\mathrm{W}$ and $\mathrm{Z}$, sex chromosomes; $\mathrm{Z}^{d z+}$, a fragment of the $\mathrm{Z}$ chromosome carrying a $d z^{+}$allele. Scale bar $=2 \mu \mathrm{m}$.

either a WZ bivalent plus an unpaired $\mathrm{Z}^{d z+}$ univalent or a $\mathrm{ZZ}^{d z+}$ bivalent plus an unpaired $\mathrm{W}$ univalent (Fig. 3b).

In LM preparations, a very long $\mathrm{WZZ}^{d z+}$ trivalent was also the predominant pairing configuration of sex chromosomes (over $80 \%$ ). The other two configurations with either a $Z^{d z+}$ univalent or $\mathrm{W}$ univalent were rare. The $Z^{d z+}$ fragment showed seven to eight chromomeres including the sixth conspicuous one (counted from the nearest $\mathrm{Z}$ end; Fig. 2g). It contained no heterochromatin. In trivalents, the $Z$ chromosome was elongated to adjust for pairing with both the normal $\mathrm{W}$ chromosome and the $\mathrm{Z}^{d z+}$ fragment (Fig. 2h). Finally, examination of metaphase I complements from mature oocytes of 


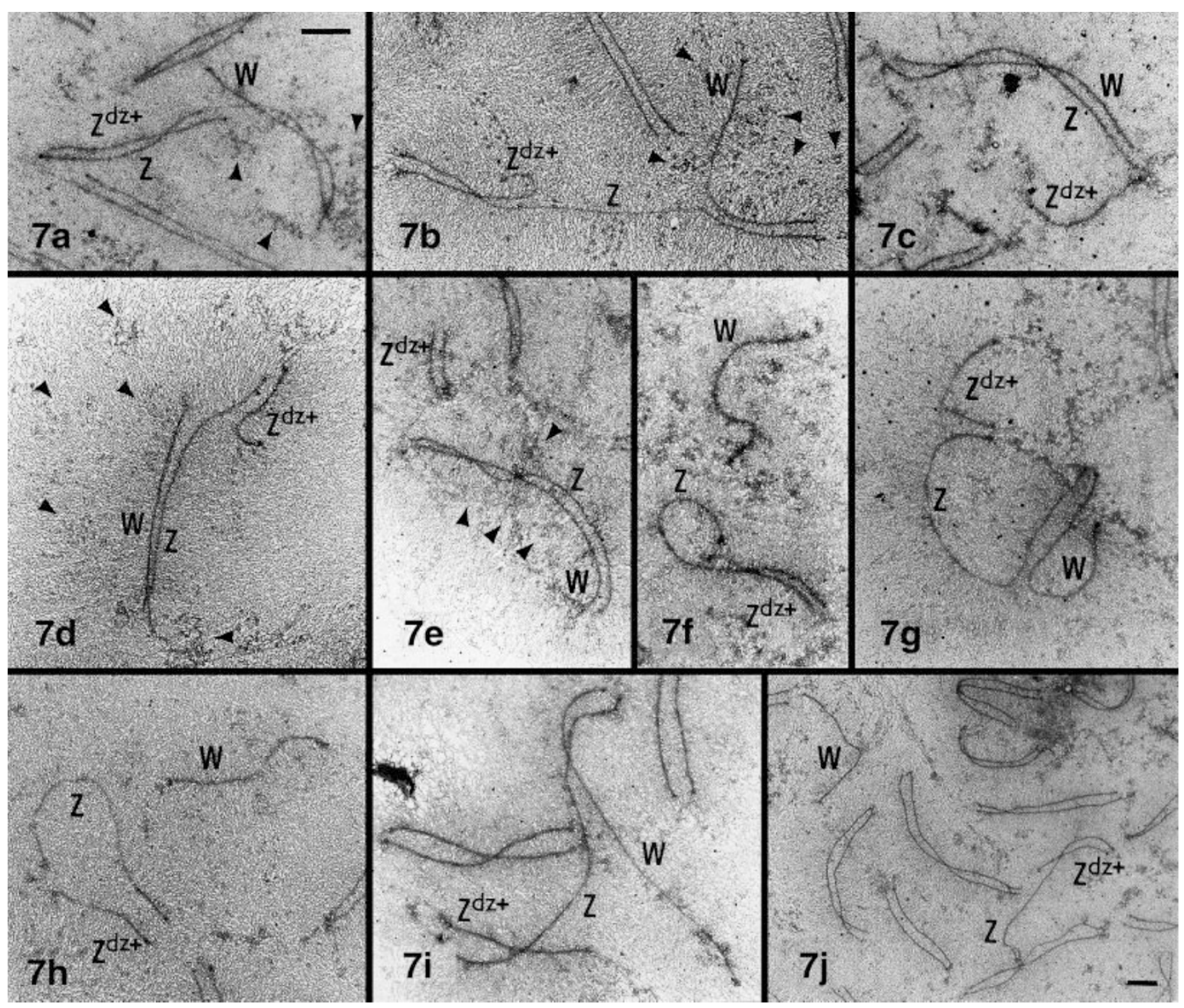

Fig. 7 Sex chromosome configurations in microspread pachytene nuclei (EM micrographs) from ASF females $\left(d z^{+}\right)$of Ephestia kuehniella. W and Z, sex chromosomes; $\mathrm{Z}^{d z+}$, a fragment of the $\mathrm{Z}$ chromosome carrying a $d z^{+}$allele. Arrowheads indicate remnants of heterochromatin tangles decorating the $\mathrm{W}$ chromosome axis. Fig. 7a,b. ASF-4 females: (a) well synapsed WZZ ${ }^{d z+}$ trivalent; (b) incompletely paired $\mathrm{WZZ}^{d z+}$ trivalent showing elongated Z-chromosome axis. Fig. 7c-e. ASF-5 females: (c) WZ bivalent and unpaired $Z^{d z+}$ univalent; (d) WZZ ${ }^{d z+}$ trivalent; (e) WZ bivalent and self-synapsed $Z^{d z+}$ univalent. Fig. 7f,g. ASF-6 females:

(f) uneven $\mathrm{ZZ}^{d z+}$ bivalent and $\mathrm{W}$ univalent; (g) partly paired $\mathrm{WZZ}^{d z+}$ trivalent. (h) ASF-7 female: uneven $\mathrm{ZZ} \mathrm{Z}^{d z+}$ bivalent and $\mathrm{W}$ univalent. Fig. 7i,j. ASF-8 females: (i) incompletely paired WZZ ${ }^{d z+}$ trivalent; (j) uneven $Z^{d z+}$ bivalent and W univalent. Scale bars $=1 \mu \mathrm{m}$. All figures except Fig. $7 \mathrm{j}$ have the same scale.

adults confirmed the presence of the $\mathrm{Z}^{d z+}$ fragment in wild-type females and its absence in $d z$ females (not shown).

\section{ASF-5, ASF-6, and ASF-7}

As in ASF-4, the $d z^{+}$allele in the ASF-5, ASF-6, and ASF-7 lines was transmitted to both sexes. Nonparental phenotypes in crosses between wild-type females and $d z$ males segregated in similar proportions, and their ratio to the parental phenotypes was about $1: 2$ (Table 1). The similarity in segregation data also applied to cytogenetic characteristics. A short $\mathrm{Z}^{d z+}$ fragment, corresponding to $32-35 \%$ of the Z-chromosome length (Table 2), was regularly observed in EM preparations of pachytene cells from female meiosis. The pairing configurations and their frequencies were similar in these three lines (Fig. 3c). About $50 \%$ of

(C) The Genetics Society of Great Britain, Heredity, 87, 659-671. 
nuclei showed a WZZ ${ }^{d z+}$ trivalent (Fig. 7d) that was often incompletely paired. Incomplete pairing of the trivalent was particularly characteristic for ASF-6 females (Fig. 7g). Many complements (30-40\%) displayed a WZ bivalent plus a $\mathrm{Z}^{d z+}$ univalent that formed a straight thread in some nuclei (Fig. 7c) but was mostly self-paired (Fig. 7e). In the remaining nuclei, a $\mathrm{ZZ}^{d z+}$ bivalent with LEs of very different lengths plus a straight thread of the $\mathrm{W}$ univalent were observed (Fig. 7f,h).

Three pairing configurations were also observed in LM preparations of pachytene nuclei from ASF-6 females possessing a $\mathrm{Z}^{d z+}$ fragment. Their frequencies were similar to those in EM preparations: about $60 \%$ of nuclei showed a $\mathrm{WZZ}^{d z+}$ trivalent (Fig. 2j) and almost $1 / 3$ of nuclei a WZ bivalent plus a $Z^{d z+}$ univalent that was mostly self-paired, while a $Z^{d z+}$ bivalent plus a $\mathrm{W}$ univalent were less frequent (Fig. 2k). The $\mathrm{Z}^{d z+}$ fragment appeared to consist of three chromomeres and a block of heterochromatin that could be easily mistaken as a cluster of chromomeres (Fig. 2j,k). A similar $\mathrm{Z}^{d z+}$ fragment with three chromomeres and a small block of heterochromatin resembling a large chromomere was found in ASF-7 females (Fig. 21). In contrast, no heterochromatin was seen in the $\mathrm{Z}^{d z+}$ fragment of ASF-5 females (Fig. 2i). Finally, it was not clear whether the $\mathrm{W}$ chromosome in ASF-6 and ASF-7 females was deficient at one end.

In all three lines, metaphase I complements from mature oocytes of adult wild-type females showed a small additional $\mathrm{Z}^{d z+}$ fragment, mostly paired with the original sex chromosomes in a trivalent (Fig. 6b), whereas the karyotype of $d z$ females consisted of 30 normal bivalents (not shown).

\section{ASF-8}

In the ASF- 8 line, the $d z^{+}$allele was inherited by both sexes, but wild-type female progeny were underrepresented probably because of their low viability (Table 1). Pachytene complements in ASF-8 females possessing a $\mathrm{Z}^{d z+}$ fragment showed a number of irregularities in sex chromosome pairing in spite of the fact that the fragment was relatively long $(40 \%$ of the $\mathrm{Z}$ length; Table 2). Less than $40 \%$ of nuclei displayed a $\mathrm{WZZ}^{d z+}$ trivalent, in most cases incompletely paired (Fig. 7i). Almost $50 \%$ of the nuclei contained a $\mathrm{ZZ}^{d z+}$ bivalent plus a $\mathrm{W}$ univalent, straight (Fig. $7 \mathrm{j}$ ) or self-paired. The remaining nuclei showed a WZ bivalent plus a $Z^{d z+}$ univalent (Fig. 3d). Analysis of metaphase I complements from mature oocytes confirmed the presence of $\mathrm{Z}^{d z+}$ in $d z^{+}$females and its absence in $d z$ females (not shown).

\section{Discussion}

\section{Origin of sex-chromosome fragments in ASF lines}

The study of sex chromosomes in eight ASF lines of Ephestia kuehniella confirmed our preliminary findings (Marec \& Traut, 1993a) that $d z^{+}$females in these lines possess in their genome an additional segment of the $\mathrm{Z}$ chromosome. The segment includes the $d z^{+}$allele so that those females are thus heterozygous for the Z-linked $d z$ locus.

In ASF- $3 d z^{+}$females, the $\mathrm{Z}$ chromosome segment is translocated onto one of the shorter autosomes, and their genotype is $\mathrm{WZ}^{d z} \mathrm{~A}^{d z+} \mathrm{A}$. Since the translocated segment seems to be very short (the difference in length between $\mathrm{A}^{d z+}$ and $\mathrm{A}$ was only about $15 \%$ of the $\mathrm{Z}$ length; Table 2), we conclude that the $d z$ locus is located near one end of the $Z$ chromosome, as suggested in a study on $\mathrm{T}(\mathrm{W} ; \mathrm{Z})$ translocations in E. kuehniella (Marec $\&$ Traut, 1994).

In the other ASF lines, $d z^{+}$females possess a sexchromosome fragment marked with the $d z^{+}$allele $\left(\mathrm{Z}^{d z+}\right)$ in addition to the WZ sex-chromosome pair. Thus, those females exhibit three sex chromosomes ( $\mathrm{WZZ}^{d z+}$ ), and their diploid karyotype consists of $2 n=61$ elements instead of $2 n=60$. In ASF-4 and ASF-5 females, the $\mathrm{Z}^{d z+}$ fragment displayed a chromomere pattern homologous to a terminal segment of the $\mathrm{Z}$ chromosome. Hence a single break may have been sufficient to give rise to the $\mathrm{Z}^{d z+}$ from the original $\mathrm{Z}$ chromosome after irradiation of WT-C females (Marec \& Mirchi, 1990). In lines ASF-1, ASF-2, ASF-6, and ASF-7, our data strongly suggest that the $\mathrm{Z}^{d z+}$ consists of two parts, a terminal segment from the original $\mathrm{Z}$ chromosome including $2-3$ chromomeres and a segment originating from the $\mathrm{W}$ chromosome. This was proven by CGH in ASF-2 females. There are at least two possible explanations for modes of origin of $\mathrm{Z}^{d z+}$ in these four lines. First, the $\mathrm{Z}^{d z+}$ segment could have been translocated by irradiation to the $\mathrm{W}$ chromosome, but subsequently set free by a break in the terminal region of the W. Alternatively, irradiation may have induced two breaks, one in the $\mathrm{Z}$ and the other in the $\mathrm{W}$, with subsequent fusion of the two resulting terminal fragments. Both options would lead to a terminal deficiency in the $\mathrm{W}$ chromosome. Accordingly, a deficient $\mathrm{W}$ chromosome $\left(\mathrm{W}^{\mathrm{del}}\right)$ was found in the ASF-1 and ASF-2 lines. However, no shortening of the $\mathrm{W}$ was detected in the ASF-6 and ASF-7 lines.

\section{Persistence of the chromosome fragment}

Radiation-induced chromosome fragments in species with monocentric chromosomes usually do not persist in 
the genome. By contrast, free fragments in species with holokinetic chromosomes such as mites are not necessarily lost during cell divisions (review: Wrensch et al., 1994). In the milkweed bug, Oncopeltus fasciatus (Hemiptera), chromosome fragments were shown to be transmitted through germ cells to the next generation (LaChance \& Degrugillier, 1969). Chromosomes of Lepidoptera exhibit several features typical for holokinetic chromosomes, such as the lack of distinct primary constrictions (centromeres), parallel disjunction of sister chromatids at mitotic anaphase, and a high resistance to ionizing radiation (Murakami \& Imai, 1974; LaChance \& Graham, 1984; Koval, 1996). Their kinetochores, though localized, are large (Wolf, 1996) and thus, one should expect the persistence of chromosome fragments as in typical holokinetic chromosomes. The high frequency of radiation-induced chromosome fragments (up to 1.8 per individual), found in $F_{1}$ progeny of irradiated E. kuehniella (Tothová \& Marec, 2001), confirmed this prediction.

$\mathrm{Z}^{d z+}$ fragments have persisted in ASF lines of E. kuehniella for 12 years, i.e. more than 50 generations (Marec \& Mirchi, 1990; this study). Thus, these fragments are regularly transmitted through both mitotic and meiotic cell cycles, as new chromosome entities. This means that they have retained kinetic activity. We conclude that each $\mathrm{Z}^{d z+}$ fragment possesses a piece of the original kinetochore, sufficient for attachment to the spindle and enabling chromosome segregation during anaphase.

\section{Meiotic pairing and its effect on chromosome/ phenotype segregation in ASF females}

Based on the consistency of meiotic and segregation data, we conclude that pairing behaviour of the $\mathrm{Z}^{d z+}$ fragment, which carries the $d z^{+}$allele, is responsible for the atypical segregation ratios of wild-type and $d z$ progeny in seven ASF lines (all except ASF-3). In the $\mathrm{WZZ}^{d z+}$ trivalents, which are the predominating configuration of sex chromosomes, the $Z^{d z+}$ fragment pairs with its structurally normal homologue. Therefore, one can expect that $\mathrm{Z}^{d z+}$ will segregate with the $\mathrm{W}$, simulating $\mathrm{W}$ linkage. Consequently, parental genotypes will reappear in the $\mathrm{F}_{1}$ progeny. In contrast, $\mathrm{Z}^{d z+}$ univalents segregate randomly and independently from the WZ bivalents, finally resulting in both parental $\left(\mathrm{WZ}^{d z} \mathrm{Z}^{d z+}, \mathrm{Z}^{d z} \mathrm{Z}^{d z}\right)$ and nonparental $\left(\mathrm{WZ}^{d z}\right.$, $\mathrm{Z}^{d z} \mathrm{Z}^{d z} \mathrm{Z}^{d z+}$ ) geno- and phenotypes. The third configuration observed, $\mathrm{W}$ univalent plus $\mathrm{ZZ}^{d z+}$ bivalent, will form four types of gametes, $\mathrm{WZ}^{d z+}$ and $\mathrm{Z}^{d z}$ gametes leading to the parental phenotypes, $\mathrm{WZ}^{d z}$ and $\mathrm{Z}^{d z+}$ gametes leading to nonparental phenotypes: $d z$ females $\left(\mathrm{WZ} Z^{d z} \mathrm{Z}^{d z}\right)$ and $d z^{+}$males $\left(\mathrm{Z}^{d z} \mathbf{Z}^{d z+}\right)$.
There was a positive correlation between the length of $\mathrm{Z}^{d z+}$ fragments and the frequency of $\mathrm{WZZ}^{d z+}$ trivalents (Fig. 3a-d). The longest fragment was in the ASF-4 line, where more than $70 \%$ of the nuclei displayed the trivalent. Correspondingly, the lowest percentage of nonparental phenotypes occurred in this line. On the other hand, the shortest $\mathrm{Z}^{d z+}$ fragment was observed in ASF-7. In this line, less than 50\% trivalents were observed and there was a correspondingly high number of nonparental phenotypes in the progeny. The correlation does not include ASF-8, in which a well paired trivalent was rare and the predominating configuration was a $\mathrm{W}$ univalent plus a $\mathrm{ZZ}^{d z+}$ bivalent. This fact, taken together with high sterility and low viability of $d z^{+}$females, suggests that more extensive damage was induced by irradiation in this line.

In the ASF-3 line, a WZAA ${ }^{\mathrm{Z}}$ quadrivalent was the most frequent configuration at the pachytene stage. However, a significant fraction of nuclei showed two independent bivalents, the $\mathrm{WZ}$ and $\mathrm{AA}^{\mathrm{Z}}$. In addition, we did not find a clear quadrivalent in metaphase I oocytes. Therefore, we suggest that the quadrivalent was formed during zygotene by homologous pairing, but was resolved during pachytene or later into the two bivalents. As a result the $d z^{+}$allele translocated onto the autosome exhibited autosomal inheritance. Correspondingly, $d z^{+}$and $d z$ females segregated in the progeny at a ratio of $1: 1$ (see Table 1). This hypothesis is in keeping with the results of Rasmussen (1977b), who showed in triploid Bombyx mori females that multivalents occurring at zygotene were 'corrected' during pachytene to produce bivalents. The author suggested that SCs in achiasmatic meiosis of females (but not in males with chiasmatic meiosis) tend to optimize pairing in the form of bivalents.

\section{Absence of wild-type males in ASF-1, ASF-2, and ASF-3 lines}

The meiotic pairing configurations do not, however, explain the total absence of one phenotypic category, $d z^{+}$males, in the progeny of ASF-1, ASF-2, and ASF-3. In these lines, $d z^{+}$females have the potential to produce $\mathrm{ZZ}^{d z+}$ gametes that give rise to $d z^{+}$males in the progeny. The analysis of egg hatch in the females outcrossed with $d z$ males (originating from the $d z$ strain) revealed an increased fraction of unhatched eggs that had evidently been fertilized but whose embryos had died before hatching (data not shown). The percentages roughly correspond to the expected fraction of missing $d z^{+}$males. Therefore, we assume that $d z^{+}$males in the ASF-1, ASF-2, and ASF-3 lines do arise in the zygote stage but die during embryogenesis. 
Wild-type females in the ASF-1 and ASF-2 lines displayed a $\mathrm{W}^{\text {del }} \mathrm{ZZ}^{d z+}$ trivalent. Sex chromosome trivalents have previously been described from females of several Lepidoptera species. Suomalainen (1969) interpreted trivalents found in four species (Pyralidae and Tortricidae) as a $\mathrm{Z}$ chromosome aligned with two shorter $\mathrm{W}$ chromosomes, $\mathrm{W}_{1}$ and $\mathrm{W}_{2}$, which had arisen by a break of the original $\mathrm{W}$ chromosome. Another type of sex chromosome trivalent, $\mathrm{WZ}_{1} \mathrm{Z}_{2}$ (it can be interpreted as $\mathrm{AA}^{\mathrm{W}} \mathrm{Z}$ ), was found in the genus Yponomeuta (Yponomeutidae) (Nilsson et al., 1988) and in Trabala vishnu (Lasiocampidae) (Rishi et al., 1999). In all these cases, sex chromosome segregation is regular because of the achiasmatic mode of female meiosis. A comparison of the ASF-1 and ASF-2 lines with the remaining five ASF lines, in which a small fraction of wild-type males appear, did not reveal any substantial difference in the pairing behaviour of $Z^{d z+}$ fragments that would explain the absence of wild-type males in ASF-1 and ASF-2 progenies. Given the regular segregation of trivalents in the achiasmatic female meiosis, wild-type males can only arise in these strains from univalent $Z^{d z+}$ distribution. The $\mathrm{Z}^{d z+}$ fragment therefore is to blame for a malekilling activity which makes it incompatible with male development. Since in ASF-1 and ASF-2, the Z segment of $\mathrm{Z}^{d z+}$ including the chromomere pattern was similar to that in ASF-6 and ASF-7 or even shorter than in ASF-4 and ASF-5, the only obvious structural difference is the size of the additional $\mathrm{W}$ segment at one end of $\mathrm{Z}^{d z+}$. A similar $\mathrm{W}$ segment was found in $\mathrm{Z}^{d z+}$ fragments of ASF-6 and ASF-7, but was not as large and conspicuous. It is possible that the $\mathrm{W}$ segment in $\mathrm{Z}^{d z+}$ fragments of ASF-1 and ASF-2 contains the malekilling factor. A similar male-killing action of a part of the $\mathrm{W}$ chromosome was found much earlier in the silkworm, B. mori (review: Tazima, 1964) but has never been confirmed unambiguously.

In ASF-3, the male-killing activity is linked to the autosome with the translocated $\mathrm{Z}$ fragment. We did not detect an additional W chromosome segment, however. One may speculate that $d z^{+}$male genotypes in this line are lethal because of trisomy for some important region of the $\mathrm{Z}$ chromosome. However, this is unlikely because Lepidoptera appear to tolerate different levels of $\mathrm{Z}$ chromosomal gene activity (review: Traut \& Marec, 1996). Recent studies confirm the absence of dosage compensation in B. mori (Suzuki et al., 1998, 1999). In addition, it would not be plausible that trisomy of the very short $\mathrm{Z}$ chromosome segment translocated to an autosome kills males, whereas trisomy of the much longer $\mathrm{Z}^{d z+}$ fragments in other ASF lines does not. So we cannot localize the male-killing activity of the $\mathrm{Z}-\mathrm{A}$ translocation chromosome.
Unfortunately, little is known about the sex-determining mechanism in Lepidoptera and location of primary sex-determining factors is unknown. Recent studies on the $\mathrm{W}$ chromosome in B. mori revealed a new gene determining the size of eggs (Kawamura, 1988) and new retrotransposable elements (Abe et al., 1998; Ohbayashi et al., 1998), but did not bring any light on the role of the $\mathrm{W}$ chromosome in sex control.

\section{Acknowledgements}

We thank Ms. Ivana Kollárová (České Budějovice) for rearing flour moth cultures and her excellent technical assistance. Our special thanks are due to Ms. Ulrike Eickhoff (Lübeck) for her skilled help with CGH. A part of this work was done while F.M. and K.S. were at the Institute of Biology, Medical University, Lübeck (Germany). F.M. was supported by a Research Fellowship from the Alexander von Humboldt Foundation (Bonn, Germany), K.S. received a grant from Japanese Ministry of Education and Culture. Finally, we acknowledge the support given to F.M. and A.T. from the Grant Agency of the Czech Republic (grant no. 206/00/ 0750) and from the Entomology Institute projects Z5007907 and K5052113.

\section{References}

ABE, H., OHBAYAShi, F., Shimada, T., SUgASAKI, T., KAWAI, S. AND OSHIKI, T. 1998. A complete full-length non-LTR retrotransposon, $\mathrm{BMC1}$, on the $\mathrm{W}$ chromosome of the silkworm, Bombyx mori. Genes Genet. Syst., 73, 353-358.

AUlT, J. G. AND RIEDER, C. L. 1994. Meiosis in Drosophila males. I. The question of separate conjunctive mechanisms for the XY and autosomal bivalents. Chromosoma, 103, $352-356$.

GRELL, R. F. 1971. Distributive pairing in man? Ann. Genet., 14, $165-171$.

HAWLEY, R. S., IRICK, H., ZITRON, A. E., HADDOX, D. A., LOHE, A., NEW, C. ET AL. 1992. There are 2 mechanisms of achiasmate segregation in Drosophila females, one of which requires heterochromatic homology. Dev. Genet., 13, 440-467.

HOGAN, K. M., JARRELL, G. H., RYDER, E. J. AND GREENBAUM, I. F. 1992. Heterosynapsis and axial equalization of the sex chromosomes of the northern bobwhite quail. Cytogenet. Cell Genet., 60, 131-134.

JoHN, B. 1990. Meiosis. Cambridge University Press, Cambridge.

KAWAMURA, N. 1988. The egg size determining gene, Esd, is a unique morphological marker on the $\mathrm{W}$ chromosome of Bombyx mori. Genetica, 76, 195-201.

KovAL, т. M. 1996. Moths: myths and mysteries of stress resistance. BioEssays, 18, 149-156.

Kovaleva, N. v. 1992. Distributive pairing and aneuploidy in man. Genetika, 28, 5-15 (in Russian). 
KÜHN, A. 1939. Über eine geschlechtsgekoppelte Mutation des Zeichnungsmusters $d z$ bei Ephestia kühniella Z. Biol. Zbl., 59, 347-357.

LACHANCE, L. E. AND Degrugillier, M. 1969. Chromosomal fragments transmitted through three generations in Oncopeltus (Hemiptera). Science, 166, 236-237.

LACHANCE, L. E. AND GRAHAM, C. K. 1984. Insect radiosensitivity: dose curves and dose-fractionation studies of dominant lethal mutations in the mature sperm of 4 insect species. Mutation Res., 127, 49-59.

LAPIERRE, J. M., CACHEUX, V., DA SILVA, F., COLLOT, N., HERVY, N., WISS, J. ET AL. 1998. Comparative genomic hybridization: Technical development and cytogenetic aspects for routine use in clinical laboratories. Ann. Genet. (Paris), 41, 56-62.

MAREC, F. 1996. Synaptonemal complexes in insects. Int. J. Insect Morph. Embryol., 25, 205-233.

MAREC, F. AND MIRCHI, R. 1990. Genetic control of the pest Lepidoptera: Gamma-ray induction of translocations between sex chromosomes of Ephestia kuehniella Zeller (Lepidoptera: Pyralidae). J. Stored Prod. Res., 26, 109-116.

MAREC, F. AND TRAUT, W. 1993a. Analysis of structural rearrangements of Lepidoptera chromosomes using the centrifugation spreading technique. In: Howard-Kitto, P., Kelleher, R. F. and Ramesh, G. V. (eds) Management of Insect Pests: Nuclear and Related Molecular and Genetic Techniques, pp. 243-250. IAEA, Vienna.

MAREC, F. AND TRAUT, w. 1993b. Synaptonemal complexes in female and male meiotic prophase of Ephestia kuehniella (Lepidoptera). Heredity, 71, 394-404.

MAREC, F. AND TRAUT, w. 1994. Sex chromosome pairing and sex chromatin bodies in $\mathrm{W}-\mathrm{Z}$ translocation strains of Ephestia kuehniella (Lepidoptera). Genome, 37, 426-435.

MCKEE, B. D. 1996. The license to pair: Identification of meiotic pairing sites in Drosophila. Chromosoma, 105, 135-141.

MCKEE, B. D., HABERA, L. AND VRANA, J. A. 1992. Evidence that intergenic spacer repeats of Drosophila melanogaster rRNA genes function as $\mathrm{X}-\mathrm{Y}$ pairing sites in male meiosis, and a general model for achiasmatic pairing. Genetics, 132, 529-544.

MILLER, O. L. AND BAKKEN, A. H. 1972. Morphological studies of transcription. In: Diczfalusy, E. (ed.) Karolinska Symposium Res. Meth. Reprod. Endocrinology. 5th Symposium, Acta Endocrinol. (Suppl. 168), pp. 155-177. Copenhagen.

MURAKAMI, A. AND IMAI, H. T. 1974. Cytological evidence for holocentric chromosomes of the silkworms, Bombyx mori and B. mandarina, (Bombycidae, Lepidoptera). Chromosoma, 47, 167-178.

NILSSON, N. O., LÖFSTEDT, C. AND DÄVRING, L. 1988. Unusual sex chromosome inheritance in six species of small ermine moths (Yponomeuta, Yponomeutidae, Lepidoptera). Hereditas, 108, 259-265.

OHBAYASHI, F., SHIMADA, T., SUGASAKI, T., KAWAI, S., MiTA, K., OSHIKI, T. ET AL. 1998. Molecular structure of the copialike retrotransposable element Yokozuna on the W chromosome of the silkworm, Bombyx mori. Genes Genet. Syst., 73, 345-352.

PIGOZZI, M. I. AND SOlARI, A. J. 1999. The ZW pairs of two paleognath birds from two orders show transitional stage of sex chromosome differentiation. Chromosome Res., 7, $541-551$.
RASMUSSEN, S. W. 1977a. The transformation of the synaptonemal complex into the 'elimination chromatin' in Bombyx mori oocytes. Chromosoma, 60, 205-221.

RASMUSSEN, S. W. 1977b. Chromosome pairing in triploid females of Bombyx mori analyzed by three dimensional reconstructions of synaptonemal complexes. Carlsberg Res. Commun., 42, 163-197.

RISHI, S., SAHNI, G. AND RISHI, K. K. 1999. Inheritance of unusual sex chromosome evidenced by $\mathrm{AA}^{\mathrm{W}} \mathrm{Z}$ sex trivalent in Trabala vishnu (Lasiocampidae, Lepidoptera). Cytobios, 100, 85-94.

SOLARI, A. J. 1992. Equalization of $\mathrm{Z}$ and $\mathrm{W}$ axes in chicken and quail oocytes. Cytogenet. Cell Genet., 59, 52-56.

SUOMALAINEN, E. 1969. On the sex chromosome trivalent in some Lepidoptera females. Chromosoma, 28, 298-308.

SUZUKI, M. G., SHIMADA, T. AND KOBAYASHI, M. 1998. Absence of dosage compensation at the transcription level of a sexlinked gene in a female heterogametic insect, Bombyx mori. Heredity, 81, 275-283.

SUZUKI, M. G., SHIMADA, T. AND KOBAYASHI, M. 1999. Bm kettin, homologue of the Drosophila kettin gene, is located on the $\mathrm{Z}$ chromosome in Bombyx mori and is not dosage compensated. Heredity, 82, 170-179.

TAZIMA, Y. 1964. The Genetics of the Silkworm. Academic Press, London.

TOTHOVÁ, A. AND MAREC, F. 2001. Chromosomal principle of radiation-induced $\mathrm{F}_{1}$ sterility in Ephestia kuehniella (Lepidoptera: Pyralidae). Genome, 44, 172-184.

TRAUT, w. 1976. Pachytene mapping in the female silkworm, Bombyx mori L. (Lepidoptera). Chromosoma, 58, 275-284.

TRAUT, w. 1977. A study of recombination, formation of chiasmata and synaptonemal complexes in female and male meiosis of Ephestia kuehniella (Lepidoptera). Genetica, 47, 135-142.

TRAUT, w. 1999. The evolution of sex chromosomes in insects: Differentiation of sex chromosomes in flies and moths. Eur. J. Entomol., 96, 227-235.

TRAUT, W. AND MAREC, F. 1996. Sex chromatin in Lepidoptera. Q. Rev. Biol., 71, 239-256.

TRAUT, W. AND MAREC, F. 1997. Sex chromosome differentiation in some species of Lepidoptera (Insecta). Chromosome Res., 5, 283-291.

TRAUT, W., SAHARA, K., OTto, T. D. AND MAREC, F. 1999. Molecular differentiation of sex chromosomes probed by comparative genomic hybridization. Chromosoma, 108, 173-180.

WEITH, A. AND TRAuT, w. 1986. Synaptic adjustment, non-homologous pairing, and non-pairing of homologous segments in sex chromosome mutants of Ephestia kuehniella (Insecta, Lepidoptera). Chromosoma, 94, 125-131.

WOLF, K. W. 1996. The structure of condensed chromosomes in mitosis and meiosis of insects. Int. J. Insect Morph. Embryol., 25, 37-62.

WRENSCH, D. L., KETHLEY, J. B. AND NORTON, R. A. 1994. Cytogenetics of holokinetic chromosomes and inverted meiosis: Keys to the evolutionary success of mites, with generalizations on eukaryotes. In: Houck, M. A. (ed.) Mites: Ecological and Evolutionary Analyses of Life-History Patterns, pp. 282-343. Chapman \& Hall, New York. 